\title{
Association Between Interleukin-10 Polymorphisms and Alzheimer's Disease: A Systematic Review and Meta-Analysis
}

\author{
Danilo Di Bona ${ }^{\mathrm{a}, \mathrm{b}, \mathrm{c}}$, Claudia Rizzo ${ }^{\mathrm{a}, \mathrm{b}}$, Giuseppe Bonaventura ${ }^{\mathrm{b}, \mathrm{d}}$, Giuseppina Candore ${ }^{\mathrm{a}}$ and \\ Calogero Caruso ${ }^{\mathrm{a}, \mathrm{b}, *}$ \\ ${ }^{\mathrm{a}}$ Dipartimento di Biopatologia e Biotecnologie Mediche e Forensi, Palermo, Italy \\ ${ }^{\mathrm{b}}$ Unità Operativa di Immunoematologia e Medicina Trasfusionale, AOUP "Paolo Giaccone", Università \\ di Palermo, Palermo, Italy \\ ${ }^{\mathrm{c}}$ Istituto di Biomedicina ed Immunologia Molecolare (IBIM), CNR, Palermo, Italy \\ ${ }^{\mathrm{d}}$ Dipartimento Biomedicina Sperimentale e Neuroscienze Cliniche, Università di Palermo, Palermo, Italy
}

Handling Associate Editor: Robert Monastero

Accepted 2 January 2012

\begin{abstract}
It has been hypothesized that polymorphisms of interleukin (IL)-10 genes affect the risk of developing late onset Alzheimer's disease (AD). However, results of different studies are often inconsistent. Our aim was to investigate by metaanalysis the association of the common polymorphisms comprehensively defining the genetic variability of the IL-10 gene with AD risk. Fifteen studies investigating the association between IL-10 polymorphisms (-1082, -819, -592) and AD were found and analyzed. The model-free approach was applied to meta-analyze these case-control genetic association studies. Available data suggested an association between - 1082 polymorphism and AD risk with a marginal statistical significance (GG versus AG/AA: pooled odds ratio [OR]: 0.82, 95\% confidence interval CI: 0.65-1.02) and evidence of a moderate degree of between-study heterogeneity $\left(\chi^{2}=27.13\right.$, d.f. $\left.=13, p=0.01, \mathrm{I}^{2}=52 \%\right)$. For the -819 and -592 polymorphisms, we did not find an association with $\mathrm{AD}$, but significant between-study heterogeneity made genotype data pooling unacceptable. Analysis by IL-10 haplotype showed that the -1082G/-819C/-592C haplotype is associated with a lower risk of AD, although with a marginal statistical significance, probably due to the low number of studies included (GCC versus other genotypes: OR: 0.61, 95\% CI: 0.32-1.15; $\mathrm{I}^{2}: 85 \%$ ). Current findings suggest a possible association between $-1082 \mathrm{~A}>\mathrm{G}$ polymorphism and the risk of developing AD; this effect is more evident in the oldest patients. The high degree of between-study heterogeneity, due to several underpowered studies and to other methodological problems of individual studies underlies the need for further methodologically adequate studies.
\end{abstract}

Keywords: Alzheimer's disease, IL-10, meta-analysis, polymorphisms

\section{INTRODUCTION}

Inflammation of the brain is a prominent pathological feature of Alzheimer's disease (AD) $[1,2]$.

\footnotetext{
*Correspondence to: Prof. Calogero Caruso, MD, Dipartimento di Biopatologia e Biotecnologie mediche e Forensi, Università di Palermo, Corso Tukory, 211, 90134 Palermo, Italy. Tel.: +39 0916555911; Fax: +39 091 23860793; E-mail: calogero.caruso@unipa.it.
}

The inflammatory response includes activation of microglia, astrocytes, and the complement system, as well as increased cytokine expression and acute phase proteins [2-4]. A number of polymorphisms in cytokine genes associated with inflammation have been investigated in $\mathrm{AD}$, both coding for proinflammatory cytokines, such as interleukin (IL)- $1 \alpha$, IL-1 $\beta$, IL-6, and tumor necrosis factor (TNF)- $\alpha$ genes and for anti-inflammatory cytokines, such as IL-10. 
These polymorphisms influence the production of cytokines and were shown to be correlated with different risk of AD in several studies [2-7].

The IL-10 gene, which maps on chromosome 1 (q31q32), is one of the main anti-inflammatory cytokines [8]. Three polymorphic areas are documented within the IL-10 gene cluster (-1082G/A, -819 T/C, -592C/A), which constitute three different haplotypes by various reciprocal combinations, namely GCC, ACC, ATA, which were thought to be associated respectively with high, intermediate, and low IL-10 production [9, 10].

The genetic association between IL-10 and AD has been investigated several times. The initial studies reported an association between low producing IL-10 genotypes and the risk of $\mathrm{AD}[11,12]$, but subsequent studies did not confirm the initial observations. The inconsistency between the results of different studies seems to be mainly due to the heterogeneity of the populations under study and the small sample size of most studies, resulting in little statistical power [11-25].

A recent meta-analysis on the association between the IL-10 -1082 single nucleotide polymorphism (SNP) and the risk of AD showed that subjects with the low producing genotypes are at higher risk of developing $\mathrm{AD}$ [7]. However the results of this meta-analysis were hampered by some mistakes in reporting the genotype frequencies. In this study, we updated the previous meta-analysis with recently published studies, and corrected the incorrect frequencies. We also pooled the results of all available population-based studies of the association between the other IL-10 SNPs $(-819$ and -592$)$ and $\mathrm{AD}$, to ascertain whether there is a genetic effect of IL-10 on AD susceptibility.

\section{METHODS}

\section{Selection of studies}

The primary source of the studies addressing the role of IL-10 polymorphisms in AD was the PUBMED database (from January 2003 to August 2011) limited to English language literature, and the selection of the search of the specific polymorphism (IL-10 -1082; IL-10 -819, IL-10 -592) for the search on the AlzGene database. The medical subject headings used for the PUBMED searches were "interleukin-10", "polymorphisms", and "Alzheimer's disease". The abstracts found were read to identify studies examining the genotype association between IL-10 SNP, and AD. We also performed a manual search of references cited in published articles. The studies were read in their entirety to assess their appropriateness for inclusion in the meta-analysis. Criteria for the inclusion in the analysis were: diagnosis of Alzheimer's disease according to the Diagnostic and Statistical Manual of Mental Disorders (DSM), and the National Institute of Neurological Disorders and Stroke-Alzheimer Diseases and Related Disorders (NINCDS-ADRDA) working group criteria [26], case-control studies, available genotypes.

\section{Data extraction}

Extraction of the data was independently performed by two readers (DDB and CC) who compared results and agreed on a consensus; disagreements were resolved by discussion.

\section{Statistical analysis}

To analyze our data, we used Review Manager, version 5.1, a statistical software package for managing and analyzing all aspects of a Cochrane Collaboration systematic review (Oxford, England: The Cochrane Collaboration, 1999). The overall odds ratio (OR) among the frequencies of genotypes in both cases and controls was estimated with models based on both fixed effects and random effects assumptions. The fixed effects model considers only within-study variability. The random effects model uses weights that incorporate both the within-study and between-study variance. Because of the high heterogeneity between the populations of most of the studies included in this meta-analysis, we have presented the results of random effects models that are the most conservative ones [27]. The $95 \%$ confidence interval $(95 \% \mathrm{CI})$ of the OR was also calculated as well as heterogeneity that was quantified by the $\mathrm{I}^{2}$ statistics [28]. Moreover, we excluded each study in turn, to ensure that no single study would be solely responsible for the significance of any result (so-called robust analysis). Influential analysis - that is, the exclusion of outlying studies until homogeneity has been achieved-was also used to explore heterogeneity. This method was used to examine the effect of studies identified as being aberrant in either results or conduct.

Power estimates were calculated with PS software, v. 2.1.43 [29]. Briefly, power was estimated using the number of case and controls, and the prevalence of the putative susceptibility allele or genotype in the control population.

The putative risk genotype in homozygosity (-1082 GG, putatively protecting from AD; -819 CC; 
$-592 \mathrm{CC})$, was compared to the other two aggregated genotype data (-1082 AG+AA; -819 CT+TT; -592 $\mathrm{AC}+\mathrm{AA})$, condensing the results into one statistic. This allowed us to highlight the effect of the putative risk/protecting genotype, as well as maintaining the statistical power compared to separately analyzing all possible transmission models which would have led to a loss of observation and, thus, of statistical power. Before aggregating data from genotypes, we ensured that there were no differences between these two subgroups.

As previously stated, the IL-10-1082 polymorphism was also analyzed by Zhang and colleagues in a recent meta-analysis [7]. In the Zhang study, the two putative low producing genotypes $(\mathrm{AA}+\mathrm{AG}$ analyzed collectively) were compared to the high producing genotype (GG), aiming to show a higher AD risk for subjects with the IL-10 low producing AA+AG genotypes. In our study, the complementary outcome was evaluated, that is the reduction of risk of developing AD in subjects with the putative IL-10 high producing genotype.

Subgroup analysis was used to explore and to explain the diversity in the results of different studies. We used as stratifying variables: 1) the statistical power of a study to detect an OR of 1.25 (at a significance level of 0.05 ), the average allelic OR reported for all the associative genetic studies on AD [30]; 2) ethnicity; 3) gender; 4) mean age of AD patients, 5) criteria used to determine AD diagnosis (clinical or confirmed neuropathologically or by imaging); and 6) Mini Mental State Examination (MMSE) in control population.

\section{RESULTS}

\section{Characteristics of the included studies}

Fifteen case-control studies of the association between IL-10 SNP and AD were identified by our search strategy [11-25]. The main features of the studies included in the meta-analyses are shown in Table 1. All studies had case-control design including a total of 2,708 patients and 2,948 healthy controls. The percentage of $\mathrm{AD}$ female patients was reported in 13 out of 15 studies and ranged from $42 \%$ to $78 \%$; the Cousin study [23] did not report the gender of the enrolled population, while the Giedraitis study [21] included only male patients. The median age of AD patients was 76, ranging from $64.9 \pm 7.8$ (The Cousin study [23], including not only early onset AD) to 82.2 , but it was not reported in one study [18]. The sample size of the studies varied greatly, ranging from 19 to 488 , as well as the number of controls, ranging from 20 to 475 . Neuropathological examination was performed in one out of 15 studies [19]. Imaging (magnetic resonance imaging/computerized tomography, MRI/CT) examination of the brain to support the clinical diagnosis (MRI/CT) was performed in only three studies [12, 22, 25]. In 9 out of 15 studies, healthy controls were selected by Mini-Mental Status Examination (MMSE) $[12,14-18,20,21,25]$. All studies were performed on Caucasian populations, except the study of Nishimura [16], conducted in Japan; the study of Ma [17], conducted in China; the Vural study [22], conducted in Turkey; and the Ramos study [18], conducted in the

Table 1

Characteristics of the populations included in the meta-analysis of IL-10 polymorphisms $(-1082,-819,-592)$ and AD

\begin{tabular}{|c|c|c|c|c|c|c|c|c|c|c|}
\hline \multirow[t]{2}{*}{ Study } & \multirow[t]{2}{*}{ Country } & \multicolumn{5}{|c|}{$\mathrm{AD}$} & \multicolumn{4}{|c|}{ Healthy controls } \\
\hline & & $n$ & Female $(\%)$ & Age (years) & $\mathrm{NC}$ & MRI/CT & $n$ & Age & Male $(\%)$ & MMSE \\
\hline Lio [11] & Italy & 132 & 65 & $68.9^{*}$ & No & No & 213 & - & 38 & No \\
\hline Depboylu [13] & Germany & 406 & 42 & $70.2 \pm 10$ & No & No & 251 & $66.8 \pm 10.6$ & 38 & No \\
\hline Infante [14] & Spain & 232 & 67 & $72.1 \pm 8.1$ & No & No & 191 & $79.9 \pm 7.5$ & 71 & Yes \\
\hline Scassellati [15] & Italy & 215 & - & $80.3 \pm 8.6$ & No & No & 153 & $71.2 \pm 8$ & - & Yes \\
\hline Arosio [12] & Italy & 65 & 68 & $80 \pm 2$ & No & Yes & 65 & $82 \pm 2$ & 62 & Yes \\
\hline Nishimura [16] & Japan & 172 & 60 & $77.4 \pm 9.7$ & No & No & 163 & $75.5 \pm 9.9$ & 61 & Yes \\
\hline Ma [17] & China & 95 & 78 & $77.6 \pm 5.8$ & No & No & 117 & $73 \pm 6.8$ & 75 & Yes \\
\hline Ramos [18] & U.S.A. & 265 & 62 & - & No & No & 347 & - & 63 & Yes \\
\hline Culpan [19] & France & 160 & 65 & $81.2 \pm 7.3$ & Yes & No & 92 & $79.7 \pm 7.5$ & 49 & No \\
\hline Bagnoli [20] & Italy & 222 & 60 & $69.4 \pm 7.8^{*}$ & No & No & 179 & $72.9 \pm 24$ & 70 & Yes \\
\hline Giedraitis [21] & Sweden & 86 & 0 & $82.2^{*}$ & No & No & 404 & 81.8 & 0 & Yes \\
\hline Vural [22] & Turkey & 101 & 65 & $76.2 \pm 6.8$ & No & Yes & 138 & $73.1 \pm 6.9$ & 67 & No \\
\hline Cousin [23] & U.K. & 488 & - & $64.9 \pm 9.9$ & No & No & 475 & $66.2 \pm 10.8$ & - & No \\
\hline Shawkatova [24] & Slovakia & 50 & 53 & $77.3^{*}$ & No & No & 140 & 73.1 & 11 & No \\
\hline \multirow[t]{2}{*}{ Ribizzi [25] } & Italy & 19 & 73.3 & 76.3 & No & Yes & 20 & 73.1 & 80 & Yes \\
\hline & Overall & 2708 & & & & Overall & 2948 & & & \\
\hline
\end{tabular}

*Age of onset. NC: neuropathological diagnosis. CT: Computerized tomography. MRI: Magnetic Resonance Imaging. MMSE: Mini Mental State Examination. 
USA, enrolling different ethnicities from the Seattle area.

\section{Meta-analysis: IL-10-1082 SNP}

Fourteen out of 15 studies were available for the inclusion in the meta-analysis of the association between the -1082 SNP and AD. The genotype effects for GG versus AG/AA genotypes were estimated for each of these studies (Fig. 1A). Eleven studies showed an reduced risk of developing $\mathrm{AD}$ in subjects with $\mathrm{GG}$ genotype compared to AG or AA genotypes [11-13, $15,17-19,21-24]$, but only three of them achieved statistical significance $[11,12,22]$. The pooled summary OR was 0.82 (GG versus AG/AA: OR: 0.82, 95\% CI: $0.65-1.02 ; p=0.07)$ with a marginal statistical significance using the random-effects model, suggesting that subjects with the high producing IL-10 genotype (GG) have a marginal lower risk of developing AD. There was evidence of heterogeneity between the results of individual studies (GG versus AG/AA: $\chi^{2}=27.13$, d.f. $\left.=13, p=0.01, \mathrm{I}^{2}=52 \%\right)$.

After exclusion of the Ma study [17], the one conducted in Asian population, we performed an influential analysis among studies enrolling population with similar ethnicity, which identified the study from Ribizzi [25] as the influential study. The $\mathrm{I}^{2}$ value for heterogeneity excluding this study decreased from $52 \%$ to $43 \%$ with a similar effect size (OR, -0.80 ; $95 \% \mathrm{CI},-0.65$ to -0.99$)$, but statistically significant $(p<0.004)$.

To reduce heterogeneity and to evaluate whether there was a different genotype effect in predefined subgroups of studies, we performed subgroup analysis in relation to patient (age, gender) and study characteristics (type of AD diagnosis, MMSE in controls, sample

\begin{tabular}{|c|c|c|c|c|c|c|c|c|c|c|c|}
\hline $\begin{array}{l}\text { A } \\
\text { Study or Subgroup }\end{array}$ & $\begin{array}{r}\text { AD } \\
\text { Events }\end{array}$ & Total & $\begin{array}{r}\text { HC } \\
\text { Events }\end{array}$ & Total & Weight & $\begin{array}{c}\text { Odds Ratio } \\
\text { M-H, Random, 95\% Cl }\end{array}$ & Year & & $\begin{array}{r}\text { Odds } \\
M-H, \text { Rand }\end{array}$ & $\begin{array}{l}\text { Ratio } \\
\text { om, } 95 \% \text { Cl }\end{array}$ & \\
\hline Lio 2003 [11] & 32 & 132 & 86 & 213 & $9.0 \%$ & $0.47[0.29,0.77]$ & 2003 & & -- & & \\
\hline Depboylu 2003 [13] & 56 & 233 & 25 & 97 & $8.1 \%$ & $0.91[0.53,1.57]$ & 2003 & & & & \\
\hline Infante 2004 [14] & 51 & 232 & 31 & 191 & $8.8 \%$ & $1.45[0.89,2.38]$ & 2004 & & & & \\
\hline Scassellati 2004 [15] & 35 & 215 & 26 & 153 & $7.9 \%$ & $0.95[0.54,1.66]$ & 2004 & & & & \\
\hline Arosio 2002 [12] & 4 & 63 & 14 & 63 & $2.9 \%$ & $0.24[0.07,0.77]$ & 2004 & & & & \\
\hline $\operatorname{Ma} 2005[17]$ & 3 & 85 & 5 & 117 & $2.0 \%$ & $0.73[0.17,3.14]$ & 2005 & & & & \\
\hline Culpan 2006 [19] & 41 & 160 & 24 & 92 & $7.5 \%$ & $0.98[0.54,1.75]$ & 2006 & & & & \\
\hline Ramos 2006 [18] & 65 & 265 & 100 & 347 & $11.0 \%$ & $0.80[0.56,1.15]$ & 2006 & & & & \\
\hline Bagnoli 2007 [20] & 98 & 222 & 79 & 179 & $10.5 \%$ & $1.00[0.67,1.49]$ & 2007 & & & & \\
\hline Giedraitis 2009 [21] & 13 & 84 & 97 & 385 & $6.9 \%$ & $0.54[0.29,1.03]$ & 2009 & & & & \\
\hline Vural 2009 [22] & 24 & 101 & 50 & 138 & $7.7 \%$ & $0.55[0.31,0.97]$ & 2009 & & & & \\
\hline Cousin 2009 [23] & 94 & 426 & 107 & 475 & $11.9 \%$ & $0.97[0.71,1.33]$ & 2009 & & & & \\
\hline Shawkatova 2010 [24] & 8 & 50 & 30 & 140 & $4.7 \%$ & $0.70[0.30,1.65]$ & 2010 & & & & \\
\hline Ribizzi 2010 [25] & 8 & 19 & 1 & 20 & $1.0 \%$ & $13.82[1.52,125.65]$ & 2010 & & & & \\
\hline Total $(95 \% \mathrm{Cl})$ & & 2297 & & 2610 & $100.0 \%$ & $0.82[0.65,1.02]$ & & & & & \\
\hline Total events & 532 & & 675 & & & & & & & & \\
\hline $\begin{array}{l}\text { Heterogeneity: Tau }=0 \\
\text { Test for overall effect: } Z\end{array}$ & $\begin{array}{l}\text { 8; } \mathrm{Chi}^{2}= \\
1.79(\mathrm{P}\end{array}$ & $\begin{array}{r}27.13 \\
=0.07)\end{array}$ & $d f=13(f$ & $P=0.0$ & 1); $1^{2}=52^{\circ}$ & & & 0.05 & 0.2 & $A A+A G^{5}$ & 20 \\
\hline
\end{tabular}

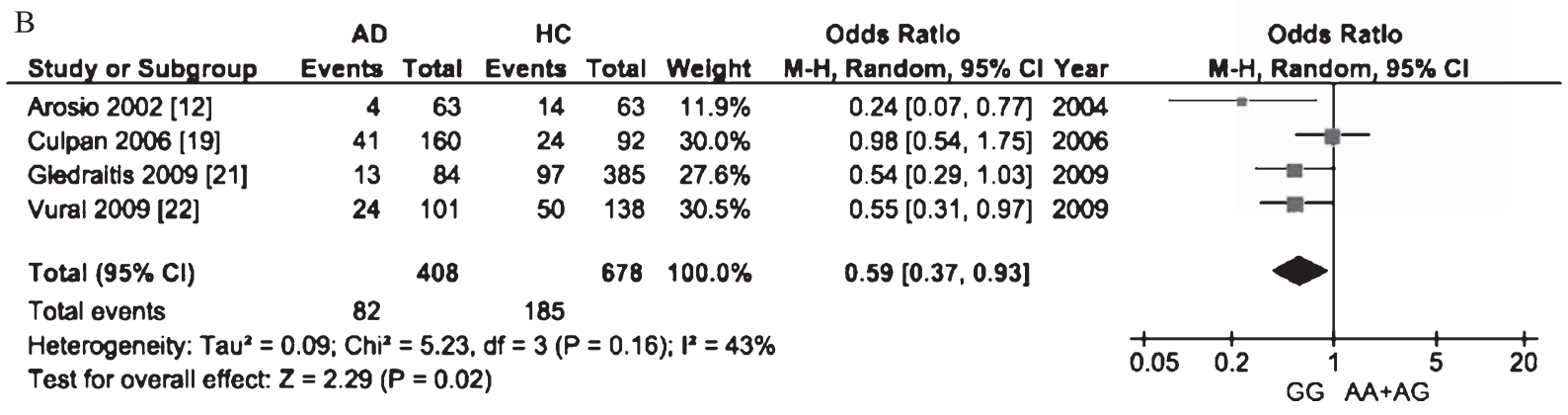

Fig. 1. A) Meta-analysis of 14 case-control studies of the IL-10 -1082 polymorphism and risk of AD using the random-effects model. B) Subgroup analysis, including studies with clinical diagnosis confirmed by MRI/CT or neuropathologic examination, on IL-10 - 1082 polymorphism and risk of Alzheimer's disease (AD) using the random-effects model. The odds ratio and 95\% confidence interval (CI) for the effect of the GG genotype on AD are plotted on the graph. Studies are arranged chronologically based on the year of publication. HC, healthy controls. 
size and statistical power of individual studies). Analyses by mean age of $\mathrm{AD}$ patients (below/above the median value of 76), showed that when the analysis included studies enrolling patients with a median age above 76 [12, 15, 17, 19, 21, 24], the GG genotype was associated with a statistically significant reduced risk of AD compared to AA and AG genotypes (OR, - 0.72; 95\% CI, -0.58 to -0.91 ). (The Ribizzi study [25] was excluded as the influential study, and the Ramos study [18] was excluded since the mean age was not reported). When we analyzed only the studies in which the clinical diagnosis was supported by MRI/CT [12, $21,22]$ together with the only retrospective study performed on neuropathologically confirmed AD patients [19], we observed a remarkable reduction in the risk of $\mathrm{AD}$ in subjects with the GG genotype, $(\mathrm{OR},-0.59$; $95 \%$ CI, -0.37 to $-0.93 ; p$ : $0.002 ; \mathrm{I}^{2}=43 \%$ ) (Fig. 1B).

Analyses by 1) mean age of healthy controls (below/above the median value of 73.1),2) percentage of female AD patients enrolled (below/above the median value of 63.5), 3) studies with/without healthy controls selected by MMSE, and 4) statistical power of individual studies (below/above the median value of 0.14 ) did not show any difference in the overall effect (data not shown).

\section{Meta-analysis: IL-10 -819 SNP}

The effect of the IL-10 -819 CC genotype on the risk of $\mathrm{AD}$ is shown in Fig. 2. Five out of 9 studies [11-13, 20, 24] showed a reduced AD risk in patients with the CC genotype compared to the other genotypes, but only two of them achieved statistical significance $[11,20]$, without evidence of significant summary OR
$(\mathrm{OR}=0.91 ; 95 \%$ C.I.: $0.60-1.37 ; p=0.65)$. A remarkable between-study heterogeneity was reported $\left(\chi^{2}\right.$ 41.18; df $8 ; p<0.00001 ; \mathrm{I}^{2}=81 \%$ ). Influence analysis showed a reduction of heterogeneity (from $\mathrm{I}^{2}=81 \%$ to $52 \%$ ) in Caucasian studies after exclusion of the studies of Scassellati [15], Ribizzi [25], and Culpan [19] with a different and statistically significant pooled estimate (OR $-0.57 ; 95 \% \mathrm{CI},-0.42$ to $-0.77 ; p<0.0003$ ). Subgroup analyses using the same study characteristics for -1082 SNP did not show any change in overall OR.

\section{Meta-analysis: IL-10 -592 SNP}

The effect of the IL-10 -592 CC genotype on the risk of $\mathrm{AD}$ is shown in Fig. 3. Four out of 9 studies [11-13, 24] showed an increased AD risk in patients with the CC genotype compared to other genotypes, but only one achieved statistical significance [11], without evidence of significant summary OR $(\mathrm{OR}=0.96$; 95\% C.I.: $0.70-1.30 ; p=0.65)$. There was evidence of high between-study heterogeneity ( $\chi^{2}$ 26.79; df $\left.8 ; p<0.0008 ; \mathrm{I}^{2}=70 \%\right)$. Influence analysis showed a reduction of heterogeneity (from $\mathrm{I}^{2}=70 \%$ to $22 \%$ ) in Caucasian studies after exclusion of the Lio study [11] with a similar pooled estimate (OR 1.02; 95\% CI, 0.82 to 1.26$)$. Subgroup analyses using the same study characteristics for -1082 SNP did not show any change in overall OR.

\section{Meta-analysis IL-10 GCC genotype}

In four out of 15 studies, the role of IL-10 haplotype was analyzed. The $-1082 \mathrm{G} /-819 \mathrm{C} /-592 \mathrm{C}$ haplotype

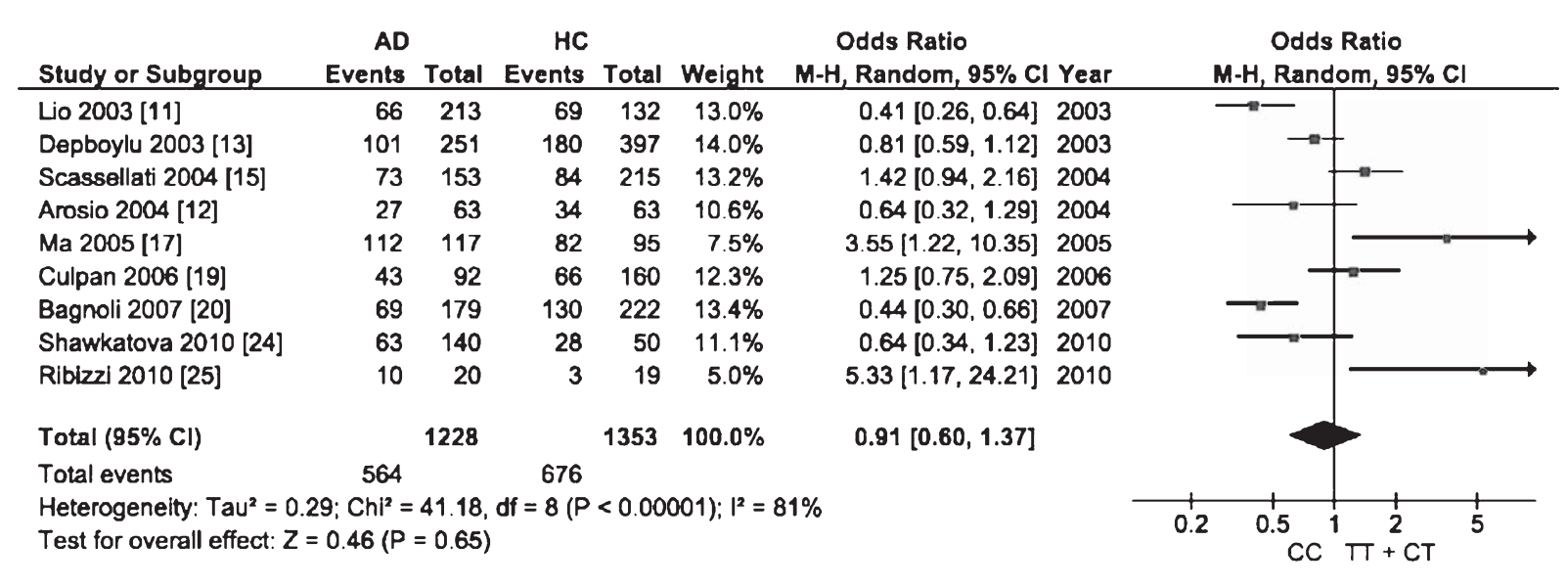

Fig. 2. Meta-analysis of 9 case-control studies of the IL-10 -819 polymorphism and risk of Alzheimer's disease (AD) using the random-effects model. The odds ratio and $95 \%$ confidence interval (CI) for the effect of the GG genotype on AD are plotted on the graph. Studies are arranged chronologically based on the year of publication. HC, healthy controls. 


\begin{tabular}{|c|c|c|c|c|c|c|c|c|c|c|c|}
\hline \multirow{2}{*}{$\begin{array}{l}\text { Study or Subgroup } \\
\text { Lio } 2003 \text { [11] }\end{array}$} & AD & Total & \multicolumn{2}{|l|}{ HC } & Weight & Odds Ratio & Year & \multicolumn{4}{|c|}{$\begin{array}{c}\text { Odds Ratio } \\
\text { M-H, Random, 95\% CI }\end{array}$} \\
\hline & 66 & 213 & 69 & 132 & $12.7 \%$ & $0.41[0.26,0.64]$ & 2003 & & $\rightarrow-$ & & \\
\hline Depboylu 2003 [13] & 107 & 235 & 189 & 406 & $14.6 \%$ & $0.96[0.70,1.32]$ & 2003 & & & & \\
\hline Arosio 2004 [12] & 27 & 63 & 34 & 63 & $9.1 \%$ & $0.64[0.32,1.29]$ & 2004 & & & & \\
\hline Scassellat 2004 [15] & 73 & 153 & 85 & 215 & $13.1 \%$ & $1.40[0.92,2.12]$ & 2004 & & & & \\
\hline Nishimura 2004 [16] & 147 & 163 & 149 & 167 & $9.0 \%$ & $1.11[0.55,2.26]$ & 2004 & & & & \\
\hline Ma 2005 [17] & 112 & 117 & 82 & 95 & $5.6 \%$ & $3.55[1.22,10.35]$ & 2005 & & & & \\
\hline Ramos 2006 [18] & 137 & 347 & 99 & 265 & $14.5 \%$ & $1.09[0.79,1.52]$ & 2006 & & & & \\
\hline Culpan 200619 & 37 & 83 & 57 & 160 & $11.5 \%$ & $1.19[0.71,2.02]$ & 2006 & & & & \\
\hline Shawkatova 2010 [24] & 63 & 140 & 28 & 50 & $9.8 \%$ & $0.64[0.34,1.23]$ & 2010 & & & & \\
\hline Total $(95 \% \mathrm{Cl})$ & & 1524 & & 1553 & $100.0 \%$ & $0.96[0.70,1.30]$ & & & & & \\
\hline Total events & 769 & & 792 & & & & & & & & \\
\hline $\begin{array}{l}\text { Heterogenelty: } \operatorname{Tau}^{2}=0 \\
\text { Test for overall effect: } Z\end{array}$ & $\begin{array}{l}\text { 4; } \mathrm{Chl}^{2}= \\
0.29(\mathrm{P}\end{array}$ & $\begin{array}{r}26.79 \\
=0.77)\end{array}$ & $d f=8(P$ & $=0.00$ & $08) ; 1^{2}=70$ & & & 0.05 & $\mathrm{Cc}$ & $A C+A A$ & 5 \\
\hline
\end{tabular}

Fig. 3. Meta-analysis of 9 case-control studies of the IL-10 -592 polymorphism and risk of Alzheimer's disease (AD) using the random-effects model. The odds ratio and 95\% confidence interval (CI) for the effect of the CC genotype on AD are plotted on the graph. Studies are arranged chronologically based on the year of publication. HC, healthy controls.

(GCC haplotype) is the most prevalent one and was associated with the highest IL-10 levels. The effect of the IL-10 GCC haplotype on the risk of AD is shown in Fig. 4. Three out of four studies [11, 20, 24] showed a statistically significant reduction of $\mathrm{AD}$ risk in patients with the GCC haplotype compared to other haplotypes. Only the Scassellati study [15] did not show an advantage of the GCC haplotype compared to the others.

The pooling estimate showed a clear reduction of the risk of developing $\mathrm{AD}$ in subjects with the GCC genotype ( $\mathrm{OR}=0.61 ; 95 \%$ C.I.: $0.32-1.15)$, but with a marginal statistical significance and high degree of heterogeneity $\left(\chi^{2} 20 ;\right.$ df $\left.3 ; p<0.0002 ; \mathrm{I}^{2}=85 \%\right)$.

\section{DISCUSSION}

Our meta-analysis summarized the evidence to date regarding the association between common polymorphisms that comprehensively capture the variability of IL-10 gene and the risk of AD. The available evidence is not sufficient to draw strong conclusions regarding a role of the three IL-10 SNPs that have been investigated to date in $\mathrm{AD}$. The results indicate a possible association between the IL-10 -1082 SNP and AD, while no association was revealed for the other two IL-10 SNPs analyzed.

Our results contrast with those of a recent metaanalysis on the role of IL-10 -1082 SNP in AD, showing a significant association between $A A+A G$ genotypes with the risk of $\mathrm{AD}$. In the Zhang metaanalysis [7] and in ours, the same outcome was analyzed, but the results were expressed as complementary data; the increased AD risk in subjects with the $\mathrm{AA}+\mathrm{AG}$ genotypes in the Zhang study and the reduced risk of AD in our study. The reason for the discrepancy between the results of the meta-analyses stem from the fact that the authors [7] include the study of Combarros [31], instead of the study by Infante [14], which we included in our analysis. The populations of healthy controls included in these two studies from the same

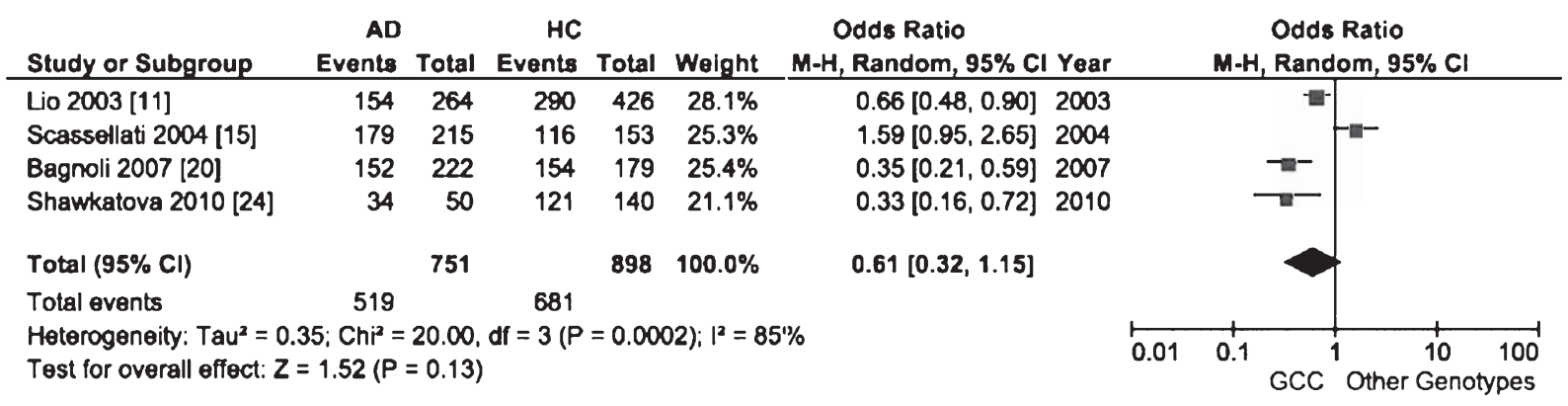

Fig. 4. Meta-analysis of 4 case-control studies of the IL-10 -1082G/-819C/-592C haplotype and risk of Alzheimer's disease (AD) using the random-effects model. The odds ratio and $95 \%$ confidence interval $(\mathrm{CI})$ for the effect of the CC genotype on AD are plotted on the graph. Studies are arranged chronologically based on the year of publication. HC, healthy controls. 
working group is almost completely overlapping, but the genotype frequencies of cases are different, leading to opposite conclusions from these two studies. We included the original study by Infante [14], since it seems in the Combarros study [31] that the same control population as the Infante study was used (historical control). Another reason explaining the inconsistency between our conclusions and those of the Zhang study [7] is related to some mistakes in reporting genotype frequencies observed in this study.

Significant heterogeneity exists between the results of individual studies. Because several potential sources of heterogeneity are present in this set of data, several steps were considered in the investigation of the causes. Influential analysis, in which one study is excluded at a time, was performed to ascertain the impact of removing each of the studies on between-study heterogeneity. This analysis identified the study by Ribizzi [25] as largely responsible for the heterogeneity of results of the -1082 SNP meta-analysis. This study was conducted on a very small sample size, only 19 patients, and showed very little statistical power, not sufficient to prevent misleading conclusions. Removing this study from the overall analysis reduced the degree of heterogeneity and led to a statistically significant association between the high IL-10 producing genotype GG in homozygosity and reduced risk of AD.

A similar procedure was performed for the -819 meta-analysis. In this case, 3 out of 9 studies were removed until heterogeneity was reduced to acceptable levels. Removing these studies [15, 19, 25] from the analysis showed a statistically significant association between the putative high IL-10 producing CC genotype and reduced risk of AD. However, in this case we were unable to define an overarching pattern of variables to differentiate the outlying samples from the rest of the data set, at least considering the aggregated data commonly present in the single studies (mean age, gender distribution, ethnicity, sample size, type of AD diagnosis, etc.).

Although all the studies investigated late-onset AD, the age range varied largely between studies, ranging from 64.9 to 82 years. Since this study characteristic could theoretically have led to heterogeneity between the results of individual studies, we attempted to control for these differences by including covariates that described the study design features. Regarding the 1082 SNP, our analysis showed that IL-10 -1082 GG is associated with a lower risk of AD only when studies enrolling patients with a median age higher than 76 years were included. No differences were found when we analyzed the studies regarding the other two SNPs.
In this regard a possible explanation could be that the meta-analyses on -819 and -592 SNPs (in contrast to the -1082 SNP analysis, which includes 14 studies) are based on a low number of studies, 7 on Caucasian and 2 on Asiatic subjects, and, therefore the subgroup analyses include a number of studies insufficient to give significant results.

While for the -1082 SNP the biological mechanism, particularly the association between the genetic polymorphism and the cytokine levels, was clearly shown in several studies, similar evidence is not available for the -819 and -592 SNPs, unless these polymorphisms are considered in the context of the entire IL-10 haplotype [8-10]. Indeed, some studies showed a reduced risk of $\mathrm{AD}$ in subjects bearing the supposed high producing IL-10 haplotype, -1082G/-819C/-592C [11, 20, 24]. In this regard our analysis suggested a role of this haplotype in the risk of $\mathrm{AD}$, but due to the small sample size of the subgroup analysis, including only 4 available studies, we could not show a statistically significant result, despite a remarkable pooled summary OR. In any case, this observation suggests the importance of the GCC haplotype in the IL-10 production or in the association with $\mathrm{AD}$ and recommend analyzing the entire haplotype rather than the single SNPs separately. Indeed, it must be noted that the association between the GCC haplotype with AD is stronger than the association of the single SNPs reported in the same 4 studies [11, 15, 20, 24] (GCC versus other genotypes: OR, 0.61; -1082 GG versus AG+AA: OR: 0.76).

The type of $\mathrm{AD}$ diagnosis could also be one of the factors influencing the results of individual studies. Only a minority of studies analyze patients with a clinical diagnosis of probable or possible AD confirmed by imaging (MRI/CT) or by neuropathological examination. When we analyzed these studies (only 4 out of 15 studies), we showed a significant summary result with a remarkable pooled OR, suggesting that an important source of heterogeneity between the results of individual studies on $\mathrm{AD}$, regarding not only the IL-10 but every SNPs considered, could be the uncertainty of the diagnosis based only on the NINCDS-ADRDA working group criteria.

However, caution must be exercised in interpreting these results since all these exploratory analyses are drawn from subgroup analyses.

This retrospective analysis has some limitations that should be acknowledged. First, one may argue that our meta-analysis does not have sufficient power to detect an OR of 0.8 or greater on the relations between IL-10 variants and the risk of $\mathrm{AD}$. It must be emphasized that almost all studies included in this meta-analysis 
are small or medium sized case-control studies, with little statistical power to detect the final OR.

Second, in two of the studies included in the meta-analysis, controls were not in Hardy-Weinberg equilibrium (HWE) [11, 17]. The sensitivity analysis, excluding these studies, did not alter the pattern of results in terms of sensitivity, but the association was not statistically significant, even after the exclusion of the influential study from Ribizzi [25]. Given the small number of studies available for the analysis, the loss of statistical significance of the sensitivity analysis excluding the studies with departure from HWE may be the result of the sample size reduction. But, it also means that the results of this meta-analysis cannot be considered robust, since the exclusion of even one study can lead to the loss of statistical significance.

Another significant limitation of this meta-analysis is that the results could not be adequately adjusted by patient characteristics or any other AD established genetic susceptibility factor, e.g., APOE $\varepsilon 4$ [2]. Only an individual patient data meta-analysis could address this issue and unveil population stratifications possibly leading to heterogeneity among study results. This could lead to clearly understanding the role of the numerous genetic associations [32, 33], many of which without unequivocal statistical support, which is, however, not unexpected given the complex multifactorial nature of AD [2]. Anyway, it is intriguing that the same SNP thought to be involved in the control of $\mathrm{AD}$ is associated with the control of atherosclerosis and favor longevity [10]. So the anti-inflammatory cytokine IL-10 and, reciprocally, the pro-inflammatory cytokine IL-6 [34, 35] are playing a crucial role in the attainment of successful or unsuccessful aging [36].

In summary, the available evidence from the present meta-analysis, based on the examination of a pooled total of 2,708 cases and 2,948 healthy controls, is not sufficient to support a protective effect of IL-10 SNPs on the risk of AD. Nevertheless, the results of this study suggest a possible role of $-1082 \mathrm{SNP}$, even in the context of the $-1082 \mathrm{G} /-819 \mathrm{C} /-592 \mathrm{C}$ haplotype, on the risk of developing $\mathrm{AD}$ and validate the need for further investigations.

\section{ACKNOWLEDGMENTS}

This meta-analysis was entirely supported by the authors' respective institutions. $\mathrm{CR}$ is a $\mathrm{PhD}$ student at the Molecular Medicine PhD course (directed by C.C.) at Palermo University and this work is submitted in partial fulfillment of the requirement for her $\mathrm{PhD}$ degree.

Authors' disclosures available online (http://www.jalz.com/disclosures/view.php?id=1124).

\section{REFERENCES}

[1] Akiyama H, Barger S, Barnum S, Bradt B, Bauer J, Cole GM, Cooper NR, Eikelenboom P, Emmerling M, Fiebich BL, Finch CE, Frautschy S, Griffin WS, Hampel H, Hull M, Landreth G, Lue L, Mrak R, Mackenzie IR, McGeer PL, O'Banion MK, Pachter J, Pasinetti G, Plata-Salaman C, Rogers J, Rydel R, Shen Y, Streit W, Strohmeyer R, Tooyoma I, Van Muiswinkel FL, Veerhuis R, Walker D, Webster S, Wegrzyniak B, Wenk G, Wyss-Coray T (2000) Inflammation and Alzheimer's disease. Neurobiol Aging 21, 383-421.

[2] Vasto S, Candore G, Listì F, Balistreri CR, Colonna-Romano G, Malavolta M, Lio D, Nuzzo D, Mocchegiani E, Di Bona D, Caruso C (2008) Inflammation, genes and zinc in Alzheimer's disease. Brain Res Rev 58, 96-105.

[3] Mrak RE, Griffin WS (2005) Glia and their cytokines in progression of neurodegeneration. Neurobiol Aging 26, 349-354.

[4] Mrak RE, Griffin WS (2005) Potential inflammatory biomarkers in Alzheimer's disease. J Alzheimers Dis 8, 369-375.

[5] Di Bona D, Plaia A, Vasto S, Cavallone L, Lescai F, Franceschi C, Licastro F, Colonna-Romano G, Lio D, Candore G, Caruso C (2008) Association between the interleukin-1 beta polymorphisms and Alzheimer's disease: A systematic review and meta-analysis. Brain Res Rev 59, 155-163.

[6] Di Bona D, Candore G, Franceschi C, Licastro F, ColonnaRomano G, Cammà C, Lio D, Caruso C (2009) Systematic review by meta-analyses on the possible role of TNF-alpha polymorphisms in association with Alzheimer's disease. Brain Res Rev 61, 60-68.

[7] Zhang Y, Zhang J, Tian C, Xiao Y, Li X, He C, Huang J, Fan H (2011) The -1082G/A polymorphism in IL-10 gene is associated with risk of Alzheimer's disease: A meta-analysis. J Neurol Sci 303, 133-138.

[8] Mosser DM, Zhang X (2008) Interleukin-10: New perspectives on an old cytokine. Immunol Rev 226, 205-218.

[9] Edwards-Smith CJ, Jonsson JR, Purdie DM, Bansal A, Shorthouse C, Powell EE (1999) Interleukin-10 promoter polymorphism predicts initial response of chronic hepatitis $\mathrm{C}$ to interferon alfa. Hepatology 30, 526-530.

[10] Lio D, Candore G, Crivello A, Scola L, Colonna-Romano G, Cavallone L, Hoffmann E, Caruso M, Licastro F, Caldarera CM, Branzi A, Franceschi C, Caruso C (2004) Opposite effects of interleukin 10 common gene polymorphisms in cardiovascular diseases and in successful ageing: Genetic background of male centenarians is protective against coronary heart disease. J Med Genet 41, 790-794.

[11] Lio D, Licastro F, Scola L, Chiappelli M, Grimaldi LM, Crivello A, Colonna-Romano G, Candore G, Franceschi C, Caruso C (2003) Interleukin-10 promoter polymorphism in sporadic Alzheimer's disease. Genes Immun 4, 234-238.

[12] Arosio B, Trabattoni D, Galimberti L, Bucciarelli P, Fasano F, Calabresi C, Cazzullo CL, Vergani C, Annoni G, Clerici M (2004) Interleukin-10 and interleukin-6 gene polymorphisms as risk factors for Alzheimer's disease. Neurobiol Aging 25, 1009-1015.

[13] Depboylu C, Du Y, Müller U, Kurz A, Zimmer R, Riemenschneider M, Gasser T, Oertel WH, Klockgether T, Dodel RC (2003) Lack of association of interleukin-10 promoter region 
polymorphisms with Alzheimer's disease. Neurosci Lett 15, 342-344.

[14] Infante J, Sanz C, Fernández-Luna JL, Llorca J, Berciano J, Combarros O (2004) Gene-gene interaction between interleukin-6 and interleukin-10 reduces AD risk. Neurology 63, 1135-1136.

[15] Scassellati C, Zanardini R, Squitti R, Bocchio-Chiavetto L, Bonvicini C, Binetti G, Zanetti O, Cassetta E, Gennarelli M (2004) Promoter haplotypes of interleukin-10 gene and sporadic Alzheimer's disease. Neurosci Lett 356, 119-122.

[16] Nishimura M, Sakamoto T, Kaji R, Kawakami H (2004) Influence of polymorphisms in the genes for cytokines and glutathione S-transferase omega on sporadic Alzheimer's disease. Neurosci Lett 368, 140-143.

[17] Ma SL, Tang NL, Lam LC, Chiu HF (2005) The association between promoter polymorphism of the interleukin-10 gene and Alzheimer's disease. Neurobiol Aging 26, 1005-1010.

[18] Ramos EM, Lin MT, Larson EB, Maezawa I, Tseng LH, Edwards KL, Schellenberg GD, Hansen JA, Kukull WA, Jin LW (2006) Tumor necrosis factor alpha and interleukin 10 promoter region polymorphisms and risk of late-onset Alzheimer disease. Arch Neurol 63, 1165-1169.

[19] Culpan D, Prince JA, Matthews S, Palmer L, Hughes A, Love S, Kehoe PG, Wilcock GK (2006) Neither sequence variation in the IL-10 gene promoter nor presence of IL-10 protein in the cerebral cortex is associated with Alzheimer's disease. Neurosci Lett 408, 141-145.

[20] Bagnoli S, Cellini E, Tedde A, Nacmias B, Piacentini S, Bessi V, Bracco L, Sorbi S (2007) Association of IL10 promoter polymorphism in Italian Alzheimer's disease. Neurosci Lett 418, 262-265.

[21] Giedraitis V, Kilander L, Degerman-Gunnarsson M, Sundelöf J, Axelsson T, Syvänen AC, Lannfelt L, Glaser A (2009) Genetic analysis of Alzheimer's disease in the uppsala longitudinal study of adult men. Dement Geriatr Cogn Disord 27, 59-68.

[22] Vural P, Değirmencioğlu S, Parildar-Karpuzoğlu H, DoğruAbbasoğlu S, Hanagasi HA, Karadağ B, Gürvit H, Emre M, Uysal M (2009) The combinations of TNFalpha-308 and IL-6 -174 or IL-10 -1082 genes polymorphisms suggest an association with susceptibility to sporadic late-onset Alzheimer's disease. Acta Neurol Scand 120, 396-401.

[23] Cousin E, Macé S, Rocher C, Dib C, Muzard G, Hannequin D, Pradier L, Deleuze JF, Génin E, Brice A, Campion D (2011) No replication of genetic association between candidate polymorphisms and Alzheimer's disease. Neurobiol Aging 32, 1443-1451.

[24] Shawkatová I, Javor J, Párnická Z, Vrazda L, Novák M, Buc M (2010) No association between cytokine gene polymorphism and risk of Alzheimer's disease in Slovaks. Acta Neurobiol Exp (Wars) 70, 303-307.
[25] Ribizzi G, Fiordoro S, Barocci S, Ferrari E, Megna M (2010) Cytokine polymorphisms and Alzheimer disease: Possible associations. Neurol Sci 31, 321-325.

[26] McKhann G, Drachman D, Folstein M, Katzman R, Price D, Stadlan EM (1984) Clinical diagnosis of Alzheimer's disease: Report of the NINCDS-ADRDA Work Group under the auspices of department of health and human services task force on Alzheimer's disease. Neurology 34, 939-944.

[27] DerSimonian R, Laird N (1986) Meta-analysis in clinical trials Controlled. Clin Trials 7, 177-188.

[28] Higgins JP, Thompson SG (2002) Quantifying heterogeneity in a meta-analysis. Stat Med 21, 1539-1558.

[29] Dupont WD, Plummer WD Jr (1990) Power and sample size calculations: A review and a computer program. Control Clin Trials 11, 116-128.

[30] Bertram L, McQueen MB, Mullin K, Blacker D, Tanzi RE (2007) Systematic meta-analyses of Alzheimer disease genetic association studies: The AlzGene database. Nat Genet 39, 17-23.

[31] Combarros O, Sánchez-Juan P, Riancho JA, Mateo $\mathrm{I}$, Rodrìguez-Rodrìguez $\mathrm{E}$, Infante $\mathrm{J}$, Garcìa-Gorostiaga I, Vázquez-Higuera JL, Berciano J (2008) Aromatase and interleukin-10 genetic variants interactively modulate Alzheimer's disease risk. J Neural Transm 115, 863-867.

[32] Candore G, Bulati M, Caruso C, Castiglia L, ColonnaRomano G, Di Bona D, Duro G, Lio D, Matranga D, Pellicanò M, Rizzo C, Scapagnini G, Vasto S (2010) Inflammation, cytokines, immune response, apolipoprotein E, cholesterol, and oxidative stress in Alzheimer disease: Therapeutic implications. Rejuvenation Res 13, 301-313.

[33] Di Bona D, Scapagnini G, Candore G, Castiglia L, ColonnaRomano G, Duro G, Nuzzo D, Iemolo F, Lio D, Pellicanò M, Scafidi V, Caruso C, Vasto S (2010) Immune-inflammatory responses and oxidative stress in Alzheimer's disease: Therapeutic implications. Curr Pharm Des 16, 684-691.

[34] Di Bona D, Vasto S, Capurso C, Christiansen L, Deiana L, Franceschi C, Hurme M, Mocchegiani E, Rea M, Lio D, Candore G, Caruso C (2009) Effect of interleukin-6 polymorphisms on human longevity: A systematic review and meta-analysis. Ageing Res Rev 8, 36-42.

[35] Licastro F, Chiappelli M, Caldarera CM, Porcellini E, Carbone I, Caruso C, Lio D, Corder EH (2011) Sharing pathogenetic mechanisms between acute myocardial infarction and Alzheimer's disease as shown by partially overlapping of gene variant profiles. J Alzheimers Dis 23, 421-431.

[36] Vasto S, Candore G, Balistreri CR, Caruso M, ColonnaRomano G, Grimaldi MP, Listi F, Nuzzo D, Lio D, Caruso C (2007) Inflammatory networks in ageing, age-relateddiseases and longevity. Mech Ageing Dev 128, 83-91. 